\title{
THE PROGRESS OF UROLOGY DURING THE LAST
}

\section{YEARS.}

\author{
By J. SWIFT JOLY, M.D., F.R.C.S. \\ (Senior Surgeon to St. Peter's Hospital for Stone.)
}

The development of Urology during the last 75 years has been so great that one may almost say it comprehends the whole of the subject as we now know it. It is difficult to imagine the state of surgery at the time St. Peter's Hospital was founded in I860. Anæsthesia had been introduced, with the result that the number of operations had greatly increased. It is doubtful if the patient benefited in any way, except that he was saved the horror of an operation without anæsthesia. Lister had not published his work on the principles of antisepsis. Every wound suppurated, and hospital gangrene was common. The surgeon operated in an old frock coat, and the more it was stained by blood and pus the more it was prized. It was his custom, on entering a ward, to glance along the floor, to see if blood was dripping on to it from an unexpected secondary hæmorrhage, while the house surgeon carried lengths of whip cord threaded through a button hole of his jacket in case his chief had to ligature a bleeding vessel. The surgery of the day was confined to the limbs and the superficial parts of the body, that of the body cavities being unknown. The only deep operation was lithotomy, and that was why the surgeon who had a stone case took precedence over all his colleagues on the day of the operation.

The two great urological diseases at this time were stone and stricture. The term "stone" connoted stone in the bladder. Renal calculus was beyond the scope of surgery, and if it could not be passed naturally, the patient was in an incurable condition. Renal surgery had not advanced since the time of Hippocrates. Perinephric abscesses were opened, but this was the sole renal operation. The wards were filled with cases of stricture, of cystitis (often undiagnosed tubercle or cancer), of enlarged prostate with retention, and of vesical calculus. The surgeon's armamentarium consisted of a set of urethral bougies, catheters and stone searchers, and special instruments such as grooved staffs and gorgets, and the lithotrite which had just been perfected. This is very different from the delicate and costly instruments of to-day.

\section{THE SURGERY OF STONE.}

When St. Peter's Hospital was founded there were two operations for vesical calculus. The first was lateral lithotomy, which was introduced by Frère Jacques towards the end of the I7th century, and placed on a firm anatomical basis by Cheselden in the early years of the I8th. For the next I50 years there was no change in it, except the introduction of anæsthesia. The second was lithotrity. The first instrument for breaking up a stone in the bladder was designed by Civiale in I8I8, but it proved to be quite unsatisfactory. In I832 Heurteloup designed an instrument somewhat similar to the present type of lithotrite, but without the locking mechanism in the handle. This latter improvement was made by the firm of Weiss of London, at the instigation of Sir Henry Thompson. Although it was possible in 1860 to crush a stone, there was no means of evacuating the fragments. The unfortunate patient had to pass them as best he could. One must admire the foresight and enthusiasm of the founders of St. Peter's hospital, 
when they put the development of this apparently unsatisfactory operation as one of the aims of the institution.

No attempt was made to crush the stone completely at one sitting. This was partly because the patient could not easily endure the pain of prolonged manipulation, but chiefly because it was believed that sepsis was induced if the instrument was kept too long in the bladder. The usual routine was to introduce the lithotrite, break off a certain amount of fragments, and allow the patient to pass them naturally. A week or ten days later, this performance was repeated, and so on until the whole of the calculus had been broken up and voided. The mortality following this operation during the early years of the hospital's existence was I5.25 per cent., and the average stay in hospital was about Ioo days. Very few patients were discharged in less than 80 days, while many remained for over I20. The operation required as a rule from 6 to I2 or even more sittings. At the present time the average stay in hospital is less than a week, and the mortality is 2 per cent.

The pain and discomfort caused by the passage of sharp angular fragments, soon led to attempts to remove them artificially. Many strange instruments were invented, but none was satisfactory. The first practical evacuator was introduced by Clover in I866, who is best remembered for his ether inhaler. He was the first to adopt the rubber bulb as a means of washing out the fragments, and all evacuators produced since his time have been made on the same principle, the only real difference being that the bulb was made of thicker rubber, and the cannulæ were larger.

The next improvement in the operation was made by Bigelow of Boston in I878. He had the advantage of being acquainted with the measurements of the urethra made by Otis, who showed that the calibre of the canal was much greater than had been hitherto supposed. He therefore increased the size of both the lithotrite and the evacuator, and was able to deal with large calculi. His great contribution to the surgical technique was the introduction of a one-stage operation. The stone was completely crushed, and all the fragments were removed at the same sitting. Bigelow's method was quickly taken up by surgeons working in India, especially by Keegan and Freyer, and their warm support of the operation was largely responsible for its introduction into this country. They also had small instruments made, so that the scope of the operation could be extended to stone occurring in childhood. Incidentally Bigelow changed the name of the operation from lithotrity to litholapaxy. ${ }^{(1)}$

The surgery of stone in the upper urinary tract was non-existent when St. Peter's Hospital was founded. In a few instances stones were found in the pus when a perinephric abscess was opened, but no one dared to incise a kidney to remove a calculus. Renal surgery dates from I869, when Gustav Simon performed the first nephrectomy. Unfortunately he lost his second patient, who died from sepsis following a digital exploration of the wound. This gave rise to the false idea that the operation was too dangerous to be really justifiable, and it was rarely performed during the next ten years. Sir Henry Morris was the first to perform a nephrolithotomy in I880, and the following year the first pyelolithotomy was performed by Beck. These two operations gave a great impetus to the surgery of the kidney, but at first there were many disappointments. The presence of a renal calculus was only surmised from the symptoms presented by the patient, and many kidneys were explored with negative results. It was not till the introduction of the X-rays, that the diagnosis could be made with any certainty. 
MacIntyre of Glasgow in I896 made the first positive diagnosis of a renal calculus by this method. His radiogram was obtained after an exposure of I2 minutes, and the diagnosis was afterwards confirmed by operation.

Radiology, however, brought a fresh series of problems in its train. Shadows were frequently observed in the renal areas or in the pelvis, which were first thought to be caused by stones, but proved on exploration to be due to other causes (tuberculous glands, phleboliths). One had to distinguish between "true" and "false" shadows. Hurry Fenwick did much pioneer work in elucidating this point, and was the first to map out the line of the ureter by passing a catheter into which a wire stylet had been previously introduced. This was subsequently developed into the opaque catheter. The introduction of instrumental pyelography by von Lichtenberg and Voelcker in I907, and of intravenous pyelography by von Lichtenberg in I929, has made it possible to determine whether any shadow seen in a radiogram is due to a calculus or to some other condition, and also to show up " transparent" stones which previously might have escaped detection. At the present time one has accurate information not only as to the size, shape, and position of the calculus before operating, but also regarding the changes it has produced in the urinary organs, and the amount of damage it has inflicted on the functional value of the kidney.

\section{SURGERY OF THE PROSTATE.}

It is difficult for us to imagine the state of a patient suffering from prostatic enlargement before the end of last century. He had to put up with the distress and inconvenience of his condition till retention finally set in. $\mathrm{He}$ was then instructed how to pass a catheter, and the only other treatment consisted in relieving complications caused by the instrument. The mortality for the first month of catheter life was Io per cent., and for the second 6 per cent. The average duration of life after the commencement of regular catheterization was stated to be about 2 years. One often hears of patients who have catheterized themselves for as long as 20 years, but they were exceptions, and probably did not account for more than one or two per cent. of the total number. Even they had a miserable existence. The bladder became inflamed, and contracted, with the result that the instrument had to be passed more and more frequently. I have seen a patient who had to relieve himself 8 times every night, and usually had to pass his instrument more than 20 times in the 24 hours. Recurrent attacks of cystitis, hæmorrhage from trauma often resulting in clot retention, false passages rendering instrumentation impossible for the patient, and vesical calculus were a few of the complications they risked. The treatment of a stone in the bladder of a prostatic was particularly unsatisfactory. One dare not open the bladder, as the wound would never heal on account of the obstruction, so litholapaxy was the only available method of treatment. This operation gave very bad results in these cases. It was impossible to crush the stone completely, or to evacuate all the fragments, as they lay out of reach in the post-prostatic pouch. The result was that the symptoms rapidly returned, and the patient only obtained transitory relief. In the old records of St. Peter's Hospital one finds the same patient returning time after time to have stones crushed. I have noted several who had I2 litholapaxies, and Freyer reported a case in which he had done a litholapaxy I6, times before "the patient was ultimately cured by removal of the prostate." These unfortunate prostatic patients filled the out-patient department in the vain hope that something could be done to relieve their suffering. 
The first prostatectomy was performed by Billroth in $\mathrm{I} 867$ for carcinoma. $\mathrm{He}$ employed the perineal route. Surgeons hesitated to operate on benign glands, because the two great authorities of the time, Sir Henry Thompson of London, and Guyon of Paris, both held that removal of the prostate would not be followed by a return of natural micturition. At a meeting of the Clinical Society of London held on IIth November I887 two papers dealing with this subject were read. The first was by Sir Henry Thompson who described a case of enlarged prostate with calculi. The patient had been on catheter life for years, but Sir Henry had opened the bladder, removed the stones, and established permanent suprapubic drainage. The man was in good health I8 months after the operation. The second was by McGill of Leeds on "Suprapubic Prostatectomy," and in it three cases were described in which the operation had been performed. McGill's operation was, however, a partial prostatectomy, as only the intravesical projection of the gland was removed. The first carefully planned perineal prostatectomy was performed by Zuckerkandl of Vienna in I889.

For the next ten years there was a curious lull in the surgery of the prostate. This may have been in some measure due to McGill's untimely death in I890, but was mainly owing to a paper written by White of Philadelphia in which he advocated castration for the relief of prostatic obstruction. This idea was quickly taken up all over the world. Subsequently vasotomy was substituted for removal of the testicles, but it took about Io years to convince the profession that these methods were ineffectual.

In I900 interest in prostatic surgery was again aroused. The perineal operation was developed by Albarran and Proust in France, and by Young in America (to mention only three among many names). These surgeons perfected a technique which has remained practically unchanged since then. In Igoo Freyer performed the first suprapubic prostatectomy in St. Peter's Hospital. This case, with three others, was reported in June I9oI. Freyer's first patient lived for I4 years after the operation, and his bladder and prostatic cavity are preserved in the Hospital's museum. There is a good deal of regeneration of prostatic tissue to be seen in the specimen, but the functional result was excellent, and there was no return of obstruction.

The essential part of Freyer's operation-the enucleation of the gland-has remained unchanged since his days, but several technical improvements have been introduced. The most important of these were a method of securing exact hæmostasis by Thomson-Walker in I920, and an ingenious method of reconstruction of the prostatic cavity by Harris of Sydney in I929. ${ }^{(2)}$

\section{TESTS OF THE RENAL FUNCTION.}

One is so much accustomed to test the excretory value of the kidneys before deciding on any operation on the urinary organs that it is difficult to visualize the time when these tests did not exist. It is still more difficult to realize that the clinical signs and symptoms of impending renal failure were recognized only in recent years. The older surgeons seem to have completely misunderstood them.

Anyone looking over the collection of calculi in the Hunterian Museum must have been struck by the immense size of the stone of Sir William Ogilvie. It weighed 40 ounces, and measured I6 inches round its greatest diameter. The catalogue of the Museum gives a long and intensely interesting account of this 
famous case. The patient was known to have the stone for 30 years, and could only pass urine when he was "almost standing on his head." In I809 Cline attempted to remove the stone through the perineum, but was only able to break off enough fragments to " fill a tea cup." The patient died ro days later, and the account in the catalogue is an admirable description of the symptoms presenter by a patient dying of renal failure, yet Cline endeavoured every day to persuade him to allow the operation to be continued. A second example is that of the famous case of Napoleon III. He was known to have a stone for many years. After the Franco-Prussian war he fled to England, and was living at Chislehurst in Kent. He then decided to allow Sir Henry Thompson to crush the stone. At that time the operation was performed in several sittings. Thompson operated twice, and apparently crushed about a third of the stone. He came down to Chislehurst to crush a further portion, but the Emperor refused to allow this to be done, much to Sir Henry's chagrin. The next day he died. The post mortem examination showed that both kidneys were pyonephrotic, yet Sir Henry does not seem to have recognized that his patient was in a parlous state when he last saw him.

It was not want of acumen that made both these surgeons misjudge the state of their patients, for both of them had an exceedingly acute clinical sense. It was rather a want of correlation between the clinical signs and the pathological changes in the kidneys. The signs of renal failure are often slight, and unless their grave import is recognized, they may easily be overlooked.

The estimation of the renal function was rendered necessary by the development of renal surgery in the eighties of last century. The estimation of the molecular content of the blood and urine by means of the lowering of the freezing point was introduced by Koranyi in I889. It was soon found that the freezing point of the urine was very variable, while that of the blood was remarkably constant. It was $-0.56^{\circ}$ in health, while a reduction to $-0.59^{\circ}$ indicated serious renal disease. It has since been shown that the lowering of the freezing point associated with renal disease is almost entirely due to an increased amount of urea in the blood. Koranyi's method has therefore been replaced by the chemical estimation of the blood urea. Many other tests of the renal function, such as the elimination of methylene blue or indigo-carmine, the excretion of sugar after an injection of phloridzin, the experimental polyuria of Albarran, were introduced during the closing years of the last century. Still the clinical signs of grave renal impairment were not fully recognized. In I908 Thomson-Walker ${ }^{(3)}$ filled this gap in our knowledge. He correlated the clinical signs with the pathological findings on the one hand, and with the tests of renal function (as they were then known) on the other hand. His work has been of the greatest importance, and nothing has been added to the clinical side of this question since then. New tests have, of course, been introduced, and our methods have become more refined and more accurate, but the foundation remains unchanged.

\section{THE CYSTOSCOPE.}

It is difficult to imagine urology without the cystoscope, yet if we turn up Sir Henry Thompson's book on "Obscure Diseases of the Bladder," we find no mention of cystoscopy in the clinical examination of the cases he recorded. One ventures to think that had cystoscopy been possible, these cases would not have been so obscure. 
Nitze has justly been called the "Father of Cystoscopy," as he was the first to introduce a source of light into the bladder. Attempts had been made previously to reflect light from an external source down a cannula placed in the urethra, and so illuminate the bladder. Desormeaux was the most successful with this type of instrument, and was able to see calculi and papillomata lying within the bladder. His instrument, however, gave a very limited view. One could see only a small portion of the bladder base, the lateral and anterior walls were quite invisible through it. Nitze made two radical changes in his instrument. The first was, as I have already stated, to introduce his source of illumination into the bladder, and the second was to incorporate an optical system (the telescope), which enabled one to observe large areas of the bladder wall. These two innovations of his are essential parts of every modern cystoscope.

Nitze introduced his first instrument in 1879 . At that time the incandescent electric lamp had not been invented, so he had to use a platinum wire heated to white heat as his source of light. This had two inconveniences. The first was that it required a powerful current to heat the wire sufficiently to give light. The second was that the heat generated by this current necessitated cooling the instrument by a current of cold water passing through it. This water circulation must not be confused with the circulation through a modern irrigating cystoscope. The water did not flow through the bladder, but only through the instrument, and its sole function was to prevent overheating. He had other difficulties to contend with. One was there was no insulated wire then on the market. He had to prepare his own by wrapping gold beater's skin round a wire of suitable calibre. Another was that he could not obtain glass tough enough to stand between his white hot wire and the water with which the bladder was filled. He had to make use of a goose quill as a window. It soon charred with the heat, and cut off the light. It is wonderful that in spite of these difficulties he was able to produce an instrument that could be used on the living, but one is not surprised that it did not become popular.

A few months after the introduction of Nitze's first cystoscope, Edison took out his first patent for incandescent electric lamps, but it was not till 8 years later that an incandescent lamp cystoscope was put on the market. It is not easy to explain the delay, but it is probable that the lamp makers had not enough skill and experience to make such small bulbs as were required. It is also possible that they were too busy making bulbs for ordinary domestic illumination to devote time and energy towards making such small lamps, the commercial value of which was quite problematical. However, the introduction of these bulbs made cystoscopy easy. The new lamp did not require to be specially cooled, so the water circulation was no longer necessary. The current could also be reduced and brought down to a safe limit, and the lamp itself had a comparatively long life. ${ }^{(4)}$

Urologists had for long desired to obtain samples of urine from each kidney in order to determine either the site of the disease, or its extent. Several instruments had been designed, which created an artificial partition between the ureteric orifices, and allowed the separated urine to drain into suitable receptacles. They had the double disadvantage that they were very painful for the patient, and that the kidney urine might become contaminated in its passage through the bladder. Efforts were consequently made to draw off the kidney urine by means of catheters inserted up the ureters. The ease with which the ureteric orifices could be seen through the cystoscope naturally stimulated this desire, but it was not till Albarran in 1897 invented his moveable lever for directing the point of the catheter towards the orifice of the ureter that a practical catheterising cystoscope was evolved. 
Since then numerous improvements have been made. The optical system has been entirely re-designed, and the modern telescope is based on the lens system used in the periscope of a submarine. In the original cystoscope, the image was reversed. This defect is now overcome by the employment of a " tectiform " or roof prism. It is interesting to note that this form of prism was originally invented for use in range-finders for artillery. Thus two war inventions have been adopted in the cystoscope. The substitution of a metallic for a carbon filament in the lamp not only improved the illumination, but also diminished the heat evolved. The last innovation was to render the whole instrument sterilizable by boiling. This was a purely British improvement, which is now being copied by other nations.

The early attempts to destroy small tumours of the bladder by means of special operating cystoscopes were not particularly successful. The usual method was to snare the tumour with a wire loop. It was impossible to remove the whole growth in this way, and recurrences were the rule. In IgII Edwin Beer of New York showed that such growths could easily be destroyed by diathermy. His method was to pass a flexible electrode through the catheter channel of an ordinary catheterising cystoscope, and to bring its extremity into contact with the tumour. The current passed through the growth and through the tissues to a large electrode placed on the abdomen. As the heating effect was only produced in the immediate neighbourhood of the vesical electrode, the growth alone was destroyed, and no harm was done to the bladder wall. This method has proved to be an immense boon to countless patients, and is used, whenever possible, in the treatment of vesical papillomata. The principle introduced by Beer has recently been extended by the discovery of the "cutting current." If the rate of oscillation is increased, the tissues are not coagulated, but are divided as if by a knife. Special instruments have been devised by which portions of the enlarged prostate can be resected by means of a loop shaped electrode, and the new type of current. It is, however, a method which is still on trial, and although it may supplant open prostatectomy in certain types of cases, it is by no means certain that it will come into universal use for all cases of prostatic obstruction.

These few examples have been selected to show the continued and rapid progress made by Urology during the last 75 years. Other examples, equally striking, might have been chosen, but these are sufficient to prove my theme. Urology has made, and is making, such progress, that the methods introduced during one decade are often obsolete the next. The rate of progress shows no signs of diminishing, and urologists all over the world are enthusiastically working for the advancement of their subject, and the benefit of humanity.

RETHENCES.

(1) For further information see Joly. "Stone and Calculus diseases of the Urinary Organs." 1929. Chap. 1.

(2) For further information see Thomson-Walker, Lettsomian Lectures, 1930 . Transactions of the Medical Society of London. Vol. liil.

(3) Thomson-Walker. "The Renal Function in Urinary Surgery," 1908.

(4) For further information see Hurry Fenwick. "The Electric Illumination of the Bladder and Urethra" 1888. Also Ringleb "Das Kystoskop" 1921. 